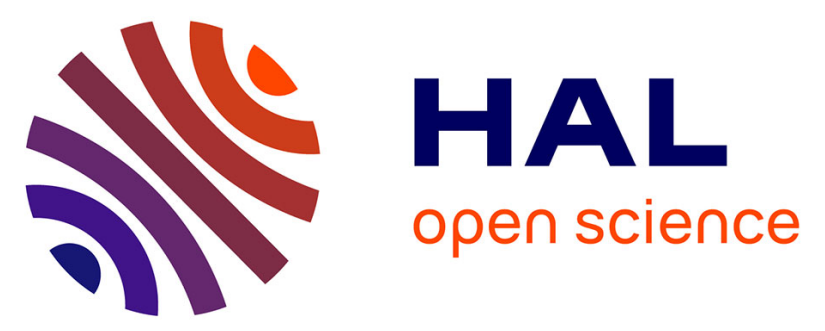

\title{
Faecal microbiota transplantation in recurrent Clostridium difficile infection: Recommendations from the French Group of Faecal microbiota Transplantation
}

Harry Sokol, Tatiana Galperine, Nathalie Kapel, Pierre Bourlioux, Philippe Seksik, Frederic Barbut, Julien Scanzi, François Chast, Rui Batista, Francisca Joly, et al.

\section{To cite this version:}

Harry Sokol, Tatiana Galperine, Nathalie Kapel, Pierre Bourlioux, Philippe Seksik, et al.. Faecal microbiota transplantation in recurrent Clostridium difficile infection: Recommendations from the French Group of Faecal microbiota Transplantation. Digestive and Liver Disease, 2016, 48 (3), pp.242247. 10.1016/j.dld.2015.08.017 . hal-01196304

\author{
HAL Id: hal-01196304 \\ https://hal.science/hal-01196304
}

Submitted on 9 Sep 2015

HAL is a multi-disciplinary open access archive for the deposit and dissemination of scientific research documents, whether they are published or not. The documents may come from teaching and research institutions in France or abroad, or from public or private research centers.
L'archive ouverte pluridisciplinaire HAL, est destinée au dépôt et à la diffusion de documents scientifiques de niveau recherche, publiés ou non, émanant des établissements d'enseignement et de recherche français ou étrangers, des laboratoires publics ou privés. 
Faecal microbiota transplantation in recurrent Clostridium difficile infection:

Recommendations from the French Group of Faecal microbiota

Transplantation

Harry Sokol $^{{ }^{*}}$, Tatiana Galperine ${ }^{2}$, Nathalie Kapel ${ }^{3}$, Pierre Bourlioux ${ }^{4,5}$, Philippe

Seksik $^{1}$, Frederic Barbut ${ }^{6}$, Julien Scanzi ${ }^{7}$, François Chast ${ }^{4,8}$, Rui Batista ${ }^{4,8}$, Francisca Joly $^{9}$, Anne-Christine Joly ${ }^{10}$, Anne Collignon ${ }^{11}$, Benoit Guery ${ }^{2}$, Laurent Beaugerie ${ }^{1}$ for the French Group of Faecal microbiota Transplantation (FGFT)*.

*see Appendix A

1 : Gastroenterology and Nutrition Department, AP-HP, Saint-Antoine Hospital F-

75012 and UPMC Paris 06 University, GRC n03, SUVIMIC, F-75012, Paris, France.

2: Infectious Diseases Department, Huriez Hospital, CHRU Lille, Lille 2 University,

France

3: Functional Coprology Laboratory, Pitié Salpêtrière Hospital - Charles Foix, AP-HP and EA 4065, Paris Descartes University, Paris, France.

4: Pharmacy Academy, 4 Avenue de l'Observatoire 75006 Paris

5: Microbiology Department-Pharmacy Faculty-Paris-Sud University

6: C. difficile National reference Laboratory, Saint-Antoine Hospital, AP-HP et

UPMC Paris 06 University, GRC N² EPIDIFF, F-75012, Paris, France

7 : Gastro-enterology Department, Hôpital Clermont-Ferrand University Hospital,

Clermont-Ferrand, France

8: Clinical Pharmacy Department, Paris University Hospital, AP-HP, Paris France

9: Gastro-enterology Department, Beaujon Hospital, AP-HP, and Paris 7 University,

Clichy, France. 
10: Pharmacy Department, preparation unit, Saint-Antoine Hospital, AP-HP, Paris 11: EA 4043, Pharmacy Faculty, Paris Sud University, France

\section{Correspondence}

Dr Harry SOKOL

Service de Gastroentérologie et Nutrition

Hôpital Saint-Antoine 184 rue du Faubourg Saint-Antoine, 75571 Paris CEDEX 12, France

Tel: +331492831 71, Fax: +33149283188 E-mail: harry.sokol@sat.aphp.fr

This work was endorsed by the French Society of Gastroenterology, the French

Society of Infectious Diseases, and the National Academy of Pharmacy. 


\section{Abstract}

Faecal microbiota transplantation is effective for treating recurrent forms of Clostridium difficile infection and its use in this indication is recommended in the most recent European and North American guidelines. In this context, faecal microbiota transplantation is beginning to be performed in France in clinical practice, while the rules governing this procedure have been defined in France only for clinical trials. To unify, secure, and evaluate practice in this field in France, the French Group of Faecal microbiota Transplantation (FGFT) was created in October 2014 with the support of the French National Society of Gastroenterology, the French Infectious Disease Society, and the National Academy of Pharmacy. We present here the deliberations of this group regarding the use of faecal microbiota transplantation for recurrent Clostridium difficile infection. The issues addressed are the indications, therapeutic sequence, delivery procedures, donor selection, $\underline{\text { methods }}$ and conditions of specimen preparation, and traceability.

Keywords : Clostridium difficile; faecal microbiota transplantation; recommendations 


\section{Introduction}

Many concordant studies, including a recently published randomised trial ${ }^{1}$, have shown that faecal microbiota transplantation (FMT) is effectivef or treating recurrent forms of Clostridium difficile infection (CDI). The use of FMT in this indication is recommended in the most recent European ${ }^{2}$ and North American ${ }^{3}$ guidelines. In this context, FMT is beginning to be performed in France in clinical practice, while the rules governing FMT have been defined in France only for clinical trials (ANSM March 2014: http://ansm.sante.fr/S-informer/Points-d-information-Points-dinformation/La-transplantation-de-microbiote-faecal-et-son-encadrement-dans-lesessais-cliniques-Point-d-information). The conditions under which FMT is performed in France are variable and not always optimal, in particular regarding the selection of donors.

Therefore, it appears necessary to provide recommendations to secure and clarify practice in this field in France. To address these issues, the French Group of Faecal microbiota Transplantation (FGFT) was created in October 2014 with the support of the French National Society of Gastroenterology (SNFGE). This initiative was received very favourably by many players in the field in France and also received the support of the French Society of Infectious Disease (SPILF) and the National Academy of Pharmacy.

Physicians, pharmacists and biologists actively involved in FMT in France gathered in December 2014 to develop recommendations to regulate the use of this procedure in clinical practice, especially in cases of multiple recurrent CDI (a recognised indication with international consensus). Indeed, recurrent $\mathrm{CDI}$ is frequent and increasing; it represents a real therapeutic problem with significant morbidity (repeated 
hospitalisations, sick leave etc.) and substantial mortality. Patients with CDI are 2.5 times more likely to die within 30 days of infection compared to uninfected patients, regardless of their age and co-morbidities ${ }^{4}$. This mortality rate could be greater in patients with the recurrent form compared to those with a single episode ${ }^{5}$. Failure to perform FMT in France within a regulatory framework and according to standard, achievable and secure procedures represents a loss of opportunity for patients in the absence of alternative treatment with similar efficacy. Given the logistical and practical issues of the procedure, particularly with regard to donor testing, it is critical to create reference centres in France and standardised procedures.

After first contact in October 2014, a panel of expert gastroenterologists and infectious diseases specialists, microbiologists, and pharmacists was established to prepare a position statement on faecal transplantation. The panel met on December $\underline{10^{\text {th }}}, 2014$ in Paris to define the timeline and milestones of the document. Regular conference calls followed and web-based data exchange were initiated. The following text represents the synthesis of the deliberations of the FGFT. It is based on the practical experience of each participant, the advice of expert microbiologists, the upstream work by the National Academy of Pharmacy, the ANSM and the analysis of practices in Europe and the United States. The issues addressed are the indications, therapeutic sequence, delivery procedures, donor selection, methods and conditions of specimen preparation, and traceability. 


\section{INDICATIONS}

In line with the recommendations of the European Society of Clinical Microbiology and Infectious Diseases (ESCMID) $2014^{2}$, the FGFT finds FMT indicated in multiple recurrent CDI (defined as more than one recurrence). FMT considered in the context of recurrent $\mathrm{CDI}$ can only be performed after failure of standard well-conducted treatment with vancomycin or fidaxomicin.

With the current state of knowledge, there are no contraindications for FMT. In particular, recent data reported good safety, even in immunocompromised patients ${ }^{6}$.

\section{THERAPEUTIC SEQUENCE}

The treatment sequence involves three steps: (i) oral antibiotic therapy with vancomycin, (ii) bowel preparation, and (iii) the delivery of the faecal suspension itself (Figure 1).

In agreement with the European guidelines, we recommend antibiotic treatment with vancomycin given orally for a minimum of four days before FMT (125 to $500 \mathrm{mg}$ four times daily). Interruption of antibiotics for 24 to $72 \mathrm{~h}$ before FMT is possible but not mandatory. Studies are currently underway to evaluate the use of fidaxomicin as a pre-treatment.

It is recommended to perform bowel preparation the day before FMT by administering $4 \mathrm{~L}$ of a bowel cleansing solution containing macrogol (polyethylene glycol [PEG]) $3350 \mathrm{cc}$ or $4000 \mathrm{cc}$ with electrolytes.

After receiving the relevant information, the patient must sign a consent form mentioning the theoretical risks of the procedure, including the risk of pathogen transmission. Consent must be signed in triplicate: one for the recipient, one for the 
patient's medical record and one for the archives (see the section below on

"Traceability").

It is recommended to monitor the recipient at least $24 \mathrm{~h}$ after the FMT procedure.

Performing FMT does not change overall patient monitoring following CDI treatment.

The literature indicates that a second FMT may be necessary in the case of failure, or recurrence after a first attempt ${ }^{1}$. This strategy is effective and recommended.

\section{DELIVERY PROCEDURES}

Three routes of delivery are possible: retention enema, during colonoscopy, or using a naso-duodenal tube.

\subsection{Retention enema}

Faecal preparation (up to $500 \mathrm{~mL}$ ) should be placed in a disposable enema bag. The preparation is dispensed by the hospital pharmacy in a disposable enema bag. The pre-lubricated cannula is inserted as far as possible according to the patient's tolerance. The administration is then performed by a nurse as usual for an enema. The patient must retain this enema as long as possible (minimum $2 \mathrm{~h}$ ). For convenience, the patient should remain lying down after insertion.

\subsection{Colonoscopy}

Faecal preparation (about $300 \mathrm{~mL}$ ) is provided by the hospital pharmacy in 50 - to 60 $\mathrm{mL}$ syringes. Colonoscopy should be performed under low pressure. Ideally, the faecal preparation should be administered upstream of the splenic flexure.

\subsection{Naso-duodenal tube}


The procedure must be carried out in the morning on an empty stomach in a patient who received treatment with proton pump inhibitors (esomeprazole $20 \mathrm{mg}$ or omeprazole $40 \mathrm{mg}$ ) the night before and 2-3 $\mathrm{h}$ before FMT. Before FMT, the tube must be placed at least in the duodenum and if possible in the proximal jejunum. The correct tube positioning should be confirmed by X-ray.

Faecal preparation $(250-500 \mathrm{~mL}$ ) is provided by the hospital pharmacy in a 50 - to 60 -

$\mathrm{mL}$ syringe (or in an enteral nutrition bag). The preparation should be administered at a rate of $50 \mathrm{~mL}$ over $2 \mathrm{~min}$. If the use of a volume greater than $250 \mathrm{~mL}$ is intended, a 10- to 15-minute pause is recommended following administration of the first $250 \mathrm{~mL}$. Patients are allowed to drink during the procedure. After administration of the faecal preparation, the naso-duodenal tube will be rinsed with tap water and left in place for 30 min before removal. Patients are then monitored for $2 \mathrm{~h}$.

The naso-duodenal route is not recommended in patients at risk of vomiting or regurgitation, because of the risk of aspiration pneumonia.

\section{DONOR SELECTION}

Although we propose absolute and relative criteria for donor selection, the severity of the patient's disease remains the prevailing factor; the rigorous application of these criteria remains at the discretion of the multidisciplinary team responsible for the implementation of FMT (doctor, pharmacist, biologist), on a case-by-case basis, depending on the urgency of the situation and on the assessment of the individual risk-benefit ratio.

\subsection{General donor pathway}


The donor must first meet criteria of the pre-selection questionnaire, to exclude any contraindications (Table 1). The donor must then undergo physical examination by a physician, including the examination of the anal margin to search for lesions attributable to human papillomavirus (HPV) or herpes simplex virus (HSV). Blood and faecal testing is then performed (Tables 2 and 3 ) to exclude infection with transmissible agents. FMT should be performed within 21 days of the screening. On the day of FMT, the donor must answer a last questionnaire (Table 4) to ensure the absence of inter-current events since the initial clinical and laboratory screening that may represent a contraindication to donation.

The donor stools must be produced on the day of FMT, and stored at $4^{\circ} \mathrm{C}$ until preparation. The maximum interval between donor stool emission and recipient delivery is $6 \mathrm{~h}$. A macrogol- or lactulose-based osmotic laxative can be administered to the donor the evening preceding FMT, to facilitate stools emission.

\subsection{Pre-selection questionnaire}

Potential donors should be evaluated thoroughly, through a questionnaire and a medical examination, to reduce the likelihood of transmission of pathogens (infectious and others).

The existing questionnaires provided for the screening of blood donors (http://www.dondusang.net/rewrite/nocache/site/37/etablissement-francais-dusang.htm?idRubrique=756) represents a solid basis to limit the risk of infection. However, additional measures should be considered to adapt the questionnaire to stool donation. In particular, it is important to collect the information specified in Table 1 , in addition to the information required for blood donation. 
After analysing the information gathered in the pre-selection questionnaire and during the interview that follows, the clinician decides whether the candidate can be selected to perform the biological screening.

This screening interview is also an opportunity to educate potential donors about the importance of limiting contamination before donation by providing recommendations in this regard (including food, travel, high-risk behaviours).

Considering the possible contamination window between the screening date and the actual FMT date, a second questionnaire and a medical interview are performed on the day of the donation. All items listed in Table 4 must be collected. After the second medical interview, according to the results of the biological screening and at the discretion of the investigator leading the interview, the donor can definitively selected for donation.

\subsection{Standard donor screening}

Blood tests should be performed in the pre-selected donor and must include: fasting glycaemia, creatinine, liver function tests (aspartate aminotrasnferase, alanine aminotrasnferase, gamma-glutmayl transpeptidase, alkaline phospatase, bilirubin), C-reactive protein, complete blood count, coagulation tests.

\subsection{Screening for infectious agents}

In FMT, the screening tests for communicable disease listed in Tables 2 and 3 should be performed in the donor. This list is not static and must be regularly reassessed on the basis of the data available in the medical literature. It was elaborated taking into account the risk of transmission of infectious agents, the means available to detect these agents on solid stools from asymptomatic individuals, and the potential severity 
of a hypothetical transmission to the recipient. The rationale for these tests is detailed in Appendix B (Supplementary Methods).

The prevention of transmission of infectious agents from a donor to a patient receiving $\mathrm{FMT}$ is based on history and microbiological testing.

None of the procedures fully guarantees against the possible transmission of a pathogen present in very small quantities and/or excreted intermittently. The likelihood of such a residual presence is impossible to quantify, but is considered low and without serious consequences at the present state of knowledge. This is mentioned in the informed consent for the recipient.

Characteristics of the ideal donor profile include: age 18-65 years,_BMI $<30$, no chronic disease, no long-term medical treatment, no travel abroad (in tropical countries at risk of infection) in the 3 months before donation, no hospitalisations abroad (in tropical countries with a risk of infection) in the 12 months before donation, normal macroscopic appearance of stools, and negative screening for infectious agents.

\subsection{Optimal timing for each procedure step (Figure 2)}

\section{$\underline{\text { 5.5.1 Between screening and donation }}$}

Using fresh stools for FMT, the faeces screened for pathogens are not those actually administered to the recipient.

The time between screening and donation must match the turnaround time for test results and be as short as possible without exceeding 21 days, to minimise the risk of contamination during this critical period.

Ideally the use of frozen donor faeces would allow microbiological testing directly on the material administered to the recipient, and would thus minimise the risk of 
transmission of infectious agents. However, no validated protocol is available regarding preparation and storage of FMT from frozen stools, although some data on effectiveness exist ${ }^{7-10}$.

\subsubsection{Between donation and transplantation}

Once prepared, the faecal suspension should be administered within $6 \mathrm{~h}$ of the bowel movement.

\subsection{Anonymous vs. directed donation}

For the indication of recurrent $C$. difficile infection, there is currently no scientific argument in favour of an anonymous donation versus a directed donation (from household contacts or relatives).

Although a directed stool donation may be possibly easier for the recipient to accept psychologically, two issues must be considered:

First, the veracity of the answers provided by the donor could be compromised by the fear of not being selected for the donation. The safety of the donation is based partly on the transparency of information provided by the donor during the medical interview and on the completeness of the questionnaire.

Second, one should consider the potential difficulty of communicating the exclusion of a close relative, and its consequences.

Conversely, one can also consider that if donor and recipient are close relatives or husband and wife, they largely share the same exposure to infectious agents. The risk of microbiological transmission could therefore be reduced. 
Consequently, no specific recommendation is made and the donor can be the spouse, a family member or have no relationship with the recipient. In all cases, the same screening tests should be carried out.

\subsection{Number of donors and recipients}

\subsubsection{One donor for multiple recipients}

The donation from one donor can be intended for different recipients. At the current state of knowledge, there are no data available that allow the identification of a preferred microbiota in healthy subjects and there is no argument in favour of a single donor directed to a single recipient.

The choice of an anonymous donor donating to multiple recipients would provide standardised material and alleviate the logistical constraints associated with the selection of donors.

\subsubsection{Multiple donors for one recipient}

Similarly, there is no argument in favour of a unique donation over "pooled" donations (i.e., a mixture of stools from several donors to prepare a single specimen). However, using "pooled" donations further complicates the problem of traceability.

\section{PREPARATION OF FMT MATERIAL}

\subsection{Setting for preparation of faecal suspension}

The pharmaceutical preparation status in France ${ }^{11}$ requires the preparation of faeces for the FMT to be carried out under the responsibility of the institution pharmacist. 
For health facilities whose pharmacy lacks the technical means and/or appropriate equipment or local logistical requirements, a subcontracting agreement can be signed with another pharmacy.

If a medical biology laboratory within the institution has the resources required to process stool, a subcontracting agreement can be made by the pharmacist, provided that the latter conducts the pharmaceutical validation at preparation release and dispensation.

\subsection{Organisation for preparing faecal microbiota}

Standardisation of the preparation method is required.

\subsubsection{Stool collection}

The stools are collected in a disposable container with a wide opening and a tight lid. The sample for FMT must not contain urine.

Given the short time (less than $6 \mathrm{~h}$ ) between the emission of stools and delivery of the preparation, a coordinated mobilisation of the pharmaceutical team (treatment of FMT sample), the biological team (collection of blood and faecal test results), and the clinical team (delivery of FMT preparation to the recipient) is needed.

\subsubsection{Dedicated room and equipment}

Preparation of stool is carried out in a dedicated room. It is performed in a biosafety cabinet to avoid the risk of cross-contamination and ensure the protection of personnel.

Operators should be protected by wearing a cassock, a cap, a disposable protective mask, protective glasses and disposable gloves.

All preparation steps are performed at room temperature. 


\subsubsection{Dilution}

The stools are diluted in sterile $\mathrm{NaCl} 0.9 \%$ to meet the isotonicity of the sample (sterile $\mathrm{NaCl} 0.9 \%$ can be refrigerated to minimise organoleptic imbalance).

A minimum of $50 \mathrm{~g}$ up to a maximum of $150 \mathrm{~g}$ of stool can be used. Homogenisation of the dilution is carried out using a dedicated materials in which elements in contact with faeces are autoclavable or disposable.

The dilution must result in a suspension with a "liquid slurry" consistency and a final volume between 200 and $500 \mathrm{~mL}$.

\section{$\underline{6.2 .4 \text { Filtration }}$}

The preparation is filtered through sterile gauze compresses placed on an autoclaveready or disposable funnel to remove large particles such as undigested food debris that may block the delivery systems.

\subsubsection{Packaging}

For delivery by naso-duodenal tube or colonoscopy, packaging is carried out in 50 to $60 \mathrm{~mL}$ syringes (3-10 syringes). When delivered via naso-duodenal tube, the faecal suspension can also be packaged in an enteral nutrition bag, opaque if possible, for better acceptability.

For delivery via enema, the packaging is a disposable enema bag $(500 \mathrm{~mL})$ with an incorporated lubricated tube.

The preparation is labelled as a pharmaceutical preparation and reports the administration route (rectal or duodenal) and formulation batch number. A welded 
labelled polyethylene overpack is used to facilitate transport. Transportation to the ward performing delivery is preferably carried out in a container at $2{ }^{\circ} \mathrm{C}$ to $8^{\circ} \mathrm{C}$.

\section{TRACEABILITY}

It is essential to ensure rigorous traceability of the FMT. For this purpose, biological samples from the donor should be stored and a batch file must be created and archived.

\subsection{Biological samples}

For each $\mathrm{FMT}$, two samples from the donor are stored at $-80^{\circ} \mathrm{C}$ :

Stool collection: $1-2 \mathrm{~g}$ of stool collected at the time of the donation, in a polypropylene tube

Sample collection: $1-5 \mathrm{~mL}$ of preparation administered to the recipient in a polypropylene tube

\subsection{Batch record data}

For each FMT, the batch record must contain:

Biological data: Stool specimen validation, blood collection validation

Relevant paperwork:_First donor screening questionnaire, second donor screening questionnaire on the day of donation, informed consent of the recipient Pharmaceutical data: origin of stools (donor identification, date and time of the donation), all technical data on preparation (manufacturing records, inspection sheet).

Samples must be stored under conditions of optimal stability at $-80^{\circ} \mathrm{C}$ for at least 3 years for each delivered sample (required to monitor possible adverse effects) and at 
least 5 years for stool (time to satisfy additional epidemiological and microbiota studies).

Recording of clinically relevant events occurring within 2 weeks of the donation is highly recommended for both donor and recipient (i.e., any infectious disease in the donor).

Finally, the creation of a national registry is strongly recommended, to record the effectiveness of the procedure and clinical events in the short and long term in both donors and recipients.

\section{Conflict of interest: none declared}

\section{Appendix A: French Group of Faecal Transplantation (FGFT)}

Laurent Alric (Toulouse), Jean-Paul Aucouturier (Reims), Aurelien Amiot (Créteil), Frederic Barbut (Paris), Rui Batista (Paris), Laurent Beaugerie (Paris), Pascale Bemer (Nantes), Robert Benamouzig (Bobigny), Nicolas Benech (Lyon), Claire

Billioud (Lyon), Gille Boschetti (Lyon), Pierre Bourlioux (Paris), Nour Boubaddi (Brive), Guillaume Bouguen (Rennes), Arnaud Bourreille (Nantes), Franck Carbonnel (Kremlin Bicêtre), Elodie Cesbron-Metivier (Angers), François Chast (Paris), Benoit Coffin (Colombes), Anne Collignon (Paris), Michael Collins (Kremlin Bicêtre), Thierry Davion (Lens), Henri Duboc (Colombes), Philippe Ducrotte (Rouen), Thibaut Fraisse (Ales), Tatiana Galperine (Lille), Benoit Guery (Lille), Marielle Guillet (Lyon), B. Heyman (Amiens), Anne-Christine Joly (Paris), Francisca Joly (Clichy), Nathalie Kapel (Paris), Alexis Mosca (Paris), Biba Nebbad (Créteil), Gabriel Perlemuter (Clamart), Jean-Marie Reimund (Strasbourg), Matthieu Revest (Rennes), Julien Scanzi (Clermont-Ferrand), Philippe Seksik (Paris), Iradj Sobhani (Créteil), Harry 
Sokol (Paris), Stephane Schneider (Nice), Caroline Trang (Nantes), Stephanie

Viennot (Caen), Maurice Viala (Nîmes), Frank Zerbib (Bordeaux). 


\section{References}

1. van Nood E, Vrieze A, Nieuwdorp M, et al. Duodenal infusion of donor feces for recurrent Clostridium difficile. N Engl J Med 2013;368:407-15.

2. Debast SB, Bauer MP, Kuijper EJ. European Society of Clinical Microbiology and Infectious Diseases: update of the treatment guidance document for Clostridium difficile infection. Clin Microbiol Infect 2014;20 Suppl 2:1-26.

3. Surawicz CM, Brandt LJ, Binion DG, et al. Guidelines for diagnosis, treatment, and prevention of Clostridium difficile infections. Am J Gastroenterol 2013;108:47898; quiz 99.

4. Hensgens MP, Goorhuis A, Dekkers OM, et al. All-cause and disease-specific mortality in hospitalized patients with Clostridium difficile infection: a multicenter cohort study. Clin Infect Dis 2013;56:1108-16.

5. Taori SK, Wroe A, Poxton IR. Clostridium difficile infections in South East Scotland: mortality and recurrence in a region without PCR ribotype 027. J Med Microbiol 2013;62:1468-77.

6. Kelly CR, Ihunnah C, Fischer M, et al. Faecal microbiota transplant for treatment of Clostridium difficile infection in immunocompromised patients. Am J Gastroenterol 2014;109:1065-71.

7. Hamilton MJ, Weingarden AR, Sadowsky MJ, et al. Standardized frozen preparation for transplantation of faecal microbiota for recurrent Clostridium difficile infection. Am J Gastroenterol 2010;107:761-7.

8. Hamilton MJ, Weingarden AR, Unno T, et al. High-throughput DNA sequence analysis reveals stable engraftment of gut microbiota following transplantation of previously frozen faecal bacteria. Gut Microbes 2013;4:125-35. 
9. Youngster I, Russell GH, Pindar C, et al. Oral, capsulized, frozen faecal microbiota transplantation for relapsing Clostridium difficile infection. JAMA 2014;312:1772-8.

10. Youngster I, Sauk J, Pindar C, et al. Faecal microbiota transplant for relapsing Clostridium difficile infection using a frozen inoculum from unrelated donors: a randomized, open-label, controlled pilot study. Clin Infect Dis 2014;58:1515-22.

11. Megerlin F, Fouassier E, Lopert R, et al. Faecal microbiota transplantation: a sui generis biological drug, not a tissue. Ann Pharm Fr 2014;72:217-20.

12. Schwartz M, Gluck M, Koon S. Norovirus gastroenteritis after faecal microbiota transplantation for treatment of Clostridium difficile infection despite asymptomatic donors and lack of sick contacts. Am J Gastroenterol 2013;108:1367.

13. Kump PK, Krause R, Allerberger F, et al. Faecal microbiota transplantation the Austrian approach. Clin Microbiol Infect 2014;20:1106-11.

14. Kump PK, Krause R, Steininger C, et al. [Recommendations for the use of faecal microbiota transplantation "stool transplantation": consensus of the Austrian Society of Gastroenterology and Hepatology (OGGH) in cooperation with the Austrian Society of Infectious Diseases and Tropical Medicine]. Z Gastroenterol 2014;52:1485-92. 


\section{Figure Legends}

Figure 1: Faecal microbiota transplantation: treatment sequence

PEG, polyethylene glycol; FMT faecal microbiota transplantation

Figure 2: Timeline for faecal microbiota transplantation donor screening, stool donation and sample preparation

FMT faecal microbiota transplantation 
Table 1 : Screening Questionnaire (specific items for stool donation)

\begin{tabular}{|c|c|c|}
\hline INFORMATION & EXCLUSION CRITERIA & $\begin{array}{l}\text { SELECTION CRITERIA WITH PERSONAL } \\
\text { ASSESSMENT }\end{array}$ \\
\hline Co-morbidities & $\begin{array}{l}\text { Digestive disorders (acute or } \\
\text { chronic diarrhea) within } 3 \text { months } \\
\text { prior to donation } \\
\text { Known chronic disease } \\
\text { History of typhoid fever }\end{array}$ & $\begin{array}{l}\text { Donors with family history of: } \\
\text { - Inflammatory bowel disease (relation) } \\
\text { - Autoimmune diseases (relation) } \\
\text { - Colon cancer (relation and age at onset) } \\
\text { Donors with personal history of } \\
\text { uncomplicated hypertension or } \\
\text { hypercholesterolemia }\end{array}$ \\
\hline Drug Treatment & $\begin{array}{l}\text { Donor under long term medical } \\
\text { treatment. }^{1} \\
\text { Antibiotic intake within } 3 \text { months }{ }^{1}\end{array}$ & $\begin{array}{l}\text { Treatment of uncomplicated hypertension } \\
\text { or hypercholesterolemia }\end{array}$ \\
\hline Travels & $\begin{array}{l}\text { Living in tropical areas during the } \\
3 \text { months prior to donation } \\
\text { Long-term residence in tropical } \\
\text { areas } \\
\text { Hospitalizations abroad longer } \\
\text { than } 24 \text { hours in the } 12 \text { months } \\
\text { prior to donation (including } \\
\text { members of the donor's } \\
\text { entourage) }\end{array}$ & $\begin{array}{l}\text { Game consumption (trichinosis screening } \\
\text { mandatory) }\end{array}$ \\
\hline Age & Minor donor ${ }^{3}$ & Aged donor ( $>65$ years) ${ }^{4}$ \\
\hline Weight status & Non limiting & Donor with Body mass index $>30^{5}$ \\
\hline
\end{tabular}

${ }^{1}$ For reasons of efficiency: the microbiota may be altered

${ }^{2}$ To avoid multiresistant bacteria colonisation

${ }^{3}$ In the absence of scientific evidence, minors should not be included, applying the general principles governing the donation and use of elements and products of the human body (art. L. 1241-2 and L. 1121-7 of the public health code)

${ }^{4}$ In the elderly, the microbiota may be modified and the risk of co-morbidities is more important

${ }^{5}$ Obese subjects have a modified microbiota and preclinical results have shown that it is possible to transfer disorders such as obesity and diabetes through the microbiota 
Table 2 : List of infectious agents to screen in donors

\begin{tabular}{|c|c|c|}
\hline & Blood (serology) & Stools \\
\hline$\frac{\pi}{8}$ & Treponema pallidum (TPHA, VDRL) & $\begin{array}{l}\text { Clostridium difficile } \\
\text { Standard stool culture : Salmonella, } \\
\text { Yersinia, Shigella, Campylobacter } \\
\text { Multiresistant bacteria } 1\end{array}$ \\
\hline$\stackrel{5}{5}$ & $\begin{array}{l}\text { HIV } \\
\text { HTLV } \\
\text { HAV, HBV, HCV, HEV } \text { CMV }^{3}\end{array}$ & $\begin{array}{l}\text { Norovirus }^{2} \\
\text { Rotavirus }^{2} \text { (only if the donor is a child } \\
\& \text { years) }\end{array}$ \\
\hline$\frac{y}{8}$ & $\begin{array}{l}\text { Strongyloïdes stercoralis }{ }^{4} \\
\text { Ameobosis }^{4} \\
\text { Trichinella sp. }^{5}\end{array}$ & $\begin{array}{l}\text { Strongylö̈des stercoralis } \\
\text { Cryptosporidium sp. } \\
\text { (immunocompromised patients). }{ }^{6} \\
\text { Cyclospora sp. }{ }^{6} \\
\text { Entamoeba histolytica }^{6,7} \\
\text { Giardia intestinalis }^{6} \\
\text { Isospora sp. }^{6} \\
\text { M icrosporidia }\end{array}$ \\
\hline
\end{tabular}

${ }^{1}$ Swab on stool samples, search for glycopeptide resistant enterococci (GRE), Extended spectrum beta-lactamase producing bacteria and Carbapenemase producing enterobacteria

${ }^{2}$ stool is examined for viruses in using molecular biology tests (PCR)

${ }^{3}$ Only to exclude sero-discordance with the recipient

${ }^{4}$ Serology if reported travel to high-risk areas

${ }^{5}$ reported game consumption only

${ }^{6}$ Parasitological examination of stool on three different samples.

${ }^{7}$ In case of travel to amoeba endemic areas, PCR for E. histolityca is recommended

TPHA, Treponema Pallidum Hemagglutinations Assay; VDRL, Veneral Disease Research Laboratory; HIV, Human Immunodeficiency Virus; HTLV, Human t-cell Leukemia Virus; HAV, Hepatitis A Virus; HBV, Hepatitis B Virus; HCV, Hepatitis C Virus; HEV, Hepatitis E Virus; CMV, Cytomegalovirus 
Table 3: Bacterial screening methods in healthy donor stool

\begin{tabular}{|l|l|}
\hline \multicolumn{1}{|c|}{ Bacteria } & \multicolumn{1}{c|}{ Recommended method (on stool) $^{1}$} \\
\hline Carbapenemase-producing bacteria & \multicolumn{1}{c|}{$\begin{array}{c}\text { Culture on two different specific media (or validated molecular } \\
\text { method) }\end{array}$} \\
\hline $\begin{array}{l}\text { Extended spectrum beta-lactamase } \\
\text { producing bacteria }\end{array}$ & Culture on specific medium \\
\hline Campylobacter sp. & $\begin{array}{l}\text { Culture on specific medium allowing spore germination (or } \\
\text { validated molecular method) }\end{array}$ \\
\hline C. difficile & Culture on specific medium after enrichment \\
\hline Salmonella sp. & Culture on specific medium \\
\hline Shigella sp. & Culture on Cefsulodin-Irgasan-Novobiocin medium \\
\hline Yersinia sp. & \\
\hline
\end{tabular}

${ }^{1}$ Each procedure uses commercialized material and should be performed following the manufacturer's recommendations. The techniques for identifying pathogens or antibiotic-resistant bacteria mentioned below should take into account the specificity of isolation on formed stools of asymptomatic donors. 
Table 4 : Screening questionnaire / Events since the screening visit

\begin{tabular}{|c|c|}
\hline EXCLUSION CRITERIA & $\begin{array}{l}\text { SELECTION on the basis of individual } \\
\text { assessment }\end{array}$ \\
\hline $\begin{array}{l}\text { Diarrhoea (>3 loose or liquid stools/ day) } \\
\text { Situations at risk of contamination: } \\
\text { - Travel in tropical areas } \\
\text { - Contact with human blood (sting, wound, showing, } \\
\text { piercing*, tattoo*) } \\
\text { - Sexual high-risk behaviour } \\
\text { - Presence of anal lesions caused by Human } \\
\text { papilloma virus or Herpes Simplex Virus }\end{array}$ & $\begin{array}{l}\text { Specific events to be investigated: } \\
\text { Medical consultation (reason) } \\
\text { Contracted disease (type, date and duration) } \\
\text { Medication (type, date of last intake) } \\
\text { Travel abroad } \\
\text { Diarrhoea (> } 3 \text { loose or liquid stools/day) } \\
\text { among members of the entourage (including } \\
\text { children) within } 4 \text { weeks of donation. }\end{array}$ \\
\hline
\end{tabular}

*if not performed in France 
Table 4 : Screening questionnaire / Events since the screening visit

\begin{tabular}{|c|c|}
\hline EXCLUSION CRITERIA & $\begin{array}{l}\text { SELECTION on the basis of individual } \\
\text { assessment }\end{array}$ \\
\hline $\begin{array}{l}\text { Diarrhoea (>3 loose or liquid stools/ day) } \\
\text { Situations at risk of contamination: } \\
\text { - Travel in tropical areas } \\
\text { - Contact with human blood (sting, wound, showing, } \\
\text { piercing*, tattoo*) } \\
\text { - Sexual high-risk behaviour } \\
\text { - Presence of anal lesions caused by Human } \\
\text { papilloma virus or Herpes Simplex Virus }\end{array}$ & $\begin{array}{l}\text { Specific events to be investigated: } \\
\text { Medical consultation (reason) } \\
\text { Contracted disease (type, date and duration) } \\
\text { Medication (type, date of last intake) } \\
\text { Travel abroad } \\
\text { Diarrhoea (> } 3 \text { loose or liquid stools/day) } \\
\text { among members of the entourage (including } \\
\text { children) within } 4 \text { weeks of donation. }\end{array}$ \\
\hline
\end{tabular}

*if not performed in France 


\section{Figure 1 \\ Figure 1}

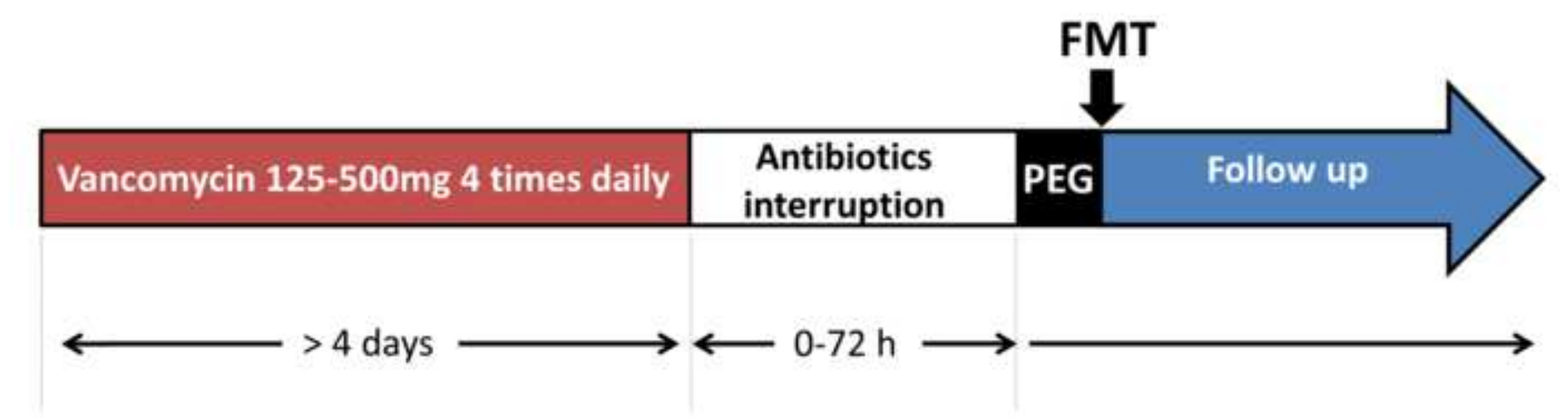

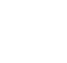




\section{Figure 2}

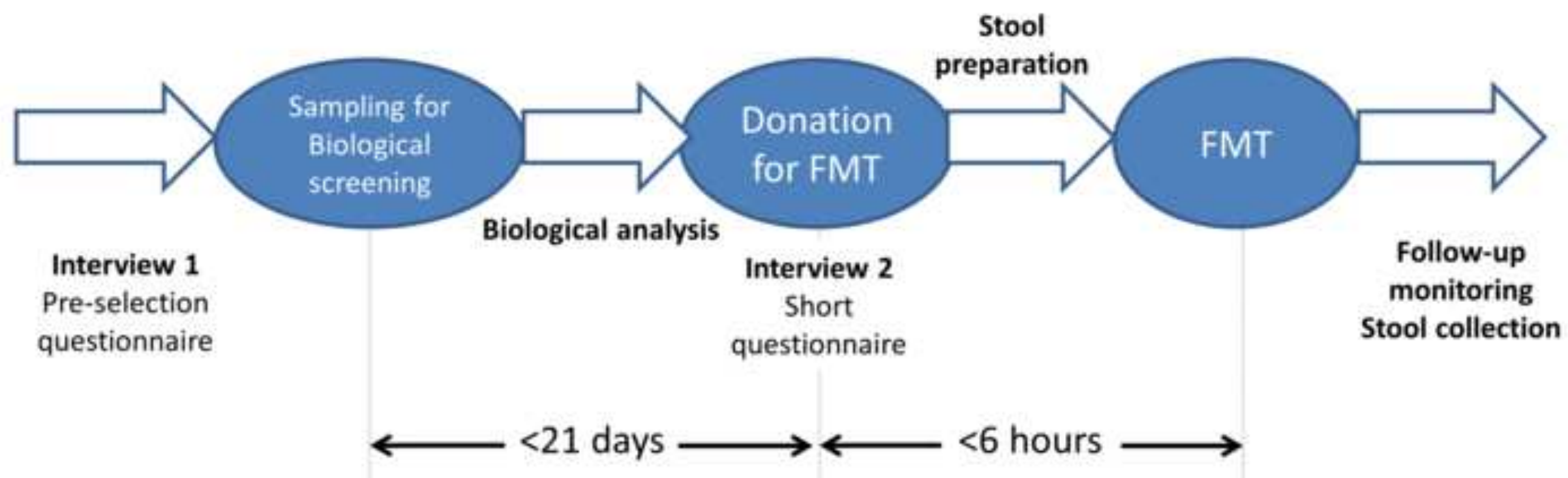

